\title{
The development of a tourism research framework by South African National Parks to inform management
}

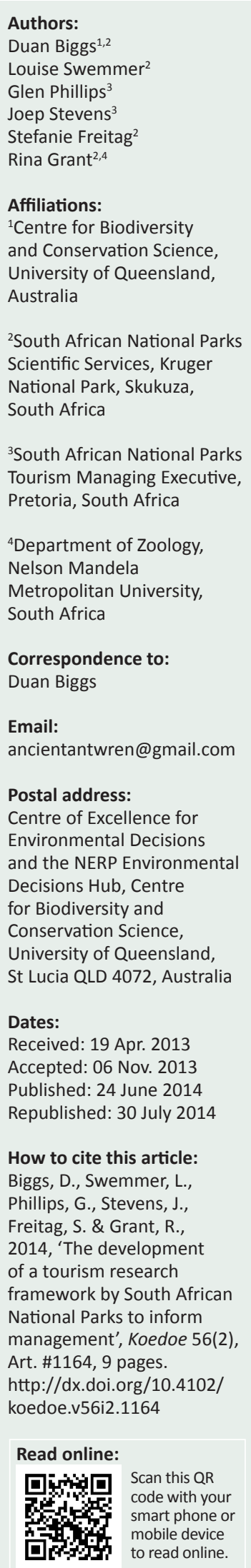

Tourism is critical source of financing for conservation in Africa. South African National Parks (SANParks) raises in excess of $80 \%$ of their own funds through tourism revenue. SANParks has a culture of co-learning between scientists and conservation managers through a process known as strategic adaptive management (SAM). Despite the critical role that tourism plays in SANParks, it has, until recently, not been formally incorporated in the SAM process. Moreover, SANParks recently adopted a new responsible tourism policy to guide the development and management of tourism across all national parks. The new policy calls for tourism that supports biodiversity conservation, is environmentally efficient and socially responsible. In 2011, SANParks initiated a tourism research programme to support the incorporation of tourism in SAM and to provide enabling information for the implementation of the responsible tourism policy. This article summarised the development of the tourism research programme in SANParks and its key research themes.

Conservation implications: An active tourism research programme that integrates science and management is necessary for tourism to play a stronger role in delivering outcomes for conservation, neighbouring communities and broader society.

\section{Introduction}

Tourism is an important and growing source of financing for protected areas (PAs) and conservation globally (Dharmaratne, Yee Sang \& Walling 2000; Naughton-Treves, Buck Holland \& Brandon 2005; Thur 2010). In Africa, the financing provided by tourism is particularly important (South African National Parks [SANParks] 2012). Yet, financing PAs and conservation through tourism presents a range of challenges. Attempts to maximise tourism revenue may have negative impacts on biodiversity conservation objectives (Grant, Peel \& Bezuidenhout 2011). Many PAs in Africa are surrounded by low income communities and challenges, trade-offs and potential synergies exist between optimising for income from visitors and delivering benefits and building and maintaining a healthy relationship with neighbouring communities (Barrett, Travis \& Dasgupta 2011; Biggs, Turpie, Fabricius \& Spenceley 2011; Botha, Witkofski \& Cock 2007; Naidoo \& Adamowicz 2005; Spenceley 2008). Indeed, the relationship between tourism, conservation and broader society forms part of a broader social-ecological system (a joint system of humans and nature) (Ban et al. 2013).

SANParks raises in excess of $80 \%$ of its annual revenue through tourism and is therefore considered one of the more successful PA agencies globally (Licht, Slotow \& Millspaugh 2008; SANParks 2012; Varghese 2008). SANParks is responsible for managing 19 national parks in South Africa, including adjoining marine PAs. The SANParks' estate includes globally renowned parks, such as Kruger National Park and Table Mountain National Park, and core protected areas in two of the planet's 25 biodiversity hotspots (Myers et al. 2000). Of the 19 PAs managed by SANParks, only a small number of iconic, internationally known PAs, such as Kruger National Park and Table Mountain National Park, operate at a profit and finance the establishment and management of many other PAs in South Africa managed by SANParks (SANParks 2012). SANParks is guided by a management philosophy and process known as strategic adaptive management (SAM) which has received widespread international exposure (Du Toit, Rogers \& Biggs 2003; Gaylard \& Ferreira 2011; Van Wilgen \& Biggs 2011; Venter et al. 2008). This has been supported by the creation of a culture of co-learning between scientific services and conservation managers (Biggs, Ferreira, Freitag-Ronaldson \& Grant-Biggs 2011; Roux \& Foxcroft 2011; Roux et al. 2006; Stirzaker, Roux \& Biggs 2011; Venter et al. 2008).

Until recently, tourism research in SANParks has taken two different forms. Firstly, is the research coordinated by the Scientific Services department, which is often conducted by outside researchers and facilitated and reviewed by SANParks Scientific Services staff (Biggs \& Rogers 2003; Gaylard

Note: Rina Grant is a Research Associate for the Department of Zoology at Nelson Mandela Metropolitan University, South Africa. This article was republished with the added affiliation for Rina Grant and note.

Copyright: @ 2014. The Authors. Licensee: AOSIS OpenJournals. This work is licensed under the Creative Commons Attribution License. 
\& Ferreira 2011). Secondly, is shorter-term research that addresses specific market issues and which is commissioned by the Tourism Development and Marketing Executive at the SANParks head office in Pretoria (hereafter the Tourism Executive). Research coordinated by Scientific Services feeds into management through bimonthly conservation meetings, forums between science and management and through scientific inputs on specific management issues. Although the conservation meetings have been conducted at regular intervals for over a decade, these typically have not involved the discussion of tourism or tourism research. The development of a tourism research framework was seen to be a way in which tourism research could strengthen how tourism is managed within the framework of SAM.

Thus, in 2011, SANParks initiated the development of a tourism research framework to better integrate tourism research and decision-making with management within the framework of SAM. In this article, we describe the development of the tourism research framework in SANParks. Firstly, we describe the context in which tourism operates in SANParks; next we describe the process that was followed to develop the tourism research framework. This is followed by a description of the research framework and a discussion of the challenges experienced in implementing the framework, as well as the lessons the SANParks' experience holds for other conservation agencies with an interest in developing tourism research.

\section{The context of tourism in South African National Parks Overview and history}

SANParks (previously the National Parks Board) was created in 1926 through an act of parliament as a parastatal organisation (Varghese 2008). The core mandate of SANParks is the conservation and management of cultural and natural heritage through a system of national parks. From its inception, SANParks was created in a way in which it was able to generate and use revenue from tourism to fulfil its mandate. Tourism in SANParks has grown exponentially since the first three tourist cars entered the Kruger National Park in 1927. This was followed by 180 cars in 1928 and 850 cars in 1929 (Stevenson-Hamilton 1937). By the 1950s, over 10000 people visited the Park each year. In the 2011-2012 financial year, national parks received a total of 4.7 million visitors, of which $77 \%$ were South African residents. Table Mountain National Park accounted for 2.3 million (49\%) guests, mainly day visitors and the Kruger National Park accounted for 1.4 million (30\%). The total revenue from tourism income, including entry fees and retail, amounted to $84 \%$ of the total income to SANParks in the 2011-2012 financial year (SANParks 2012).

Following the political change in South Africa in 1994, there has been a strong drive to increase the number of previously excluded or marginalised visitors (non-whites, defined as people of Indian, coloured, or black races) to national parks (SANParks 2012). The number of non-white visitors has increased since 1995, but not as much as desired by SANParks. In 2011-2012, 24\% of all visitors were non-white. There is a continued strong drive to increase the number of non-white visitors to national parks through developing a more diverse tourism product.

In addition, around and after the time of the political change in 1994, there was a realisation of the need to increase and diversify the income stream to national parks (Varghese 2008). One strategy that was pursued entailed the development of public-private partnerships (PPPs) and concessions in national parks. As of 2012, there are 40 active PPPs in national parks that represent $7 \%$ of total tourism revenue (SANParks 2012). The PPPs are developed and managed with a focus on achieving Black Economic Empowerment (BEE) and poverty alleviation objectives as outlined by the national government (SANParks 2012).

In 2011, SANParks adopted a responsible tourism policy to guide the development and management of tourism across all national parks (Phillips 2012). The policy aligns with new government policies and calls for tourism that supports biodiversity conservation, is environmentally efficient and socially responsible (Phillips 2012). The implementation of this policy will be based on satisfying evolving market needs, through service excellence, and the maintenance of high quality standards and infrastructure. Sound business principles will be used to generate revenue from tourism initiatives to support the SANParks conservation and constituency-building mandates (Phillips 2012).

\section{Strategic adaptive management and tourism research}

SANParks adopted SAM as the approach of choice to address the complexity inherent in managing its PAs (Venter et al. 2008). SAM consists of three components: adaptive planning (where a vision is defined together with stakeholders and the objectives that have to be met to achieve the vision are developed), adaptive implementation and, lastly, adaptive evaluation (the important step of evaluating and learning from the outcomes of the implementation) (Roux \& Foxcroft 2011). The application of SAM aims to contribute to the achievement of the SANParks vision: 'South African National Parks connecting to society' and mission: 'To develop, manage and promote a system of national parks that represents the biodiversity and heritage assets by applying best practice, environmental justice, benefit sharing and sustainable use' (SANParks 2012). Tourism has an important role to play in achieving the people's objective which is, 'to provide human benefits and build a strong constituency, preserving as far as possible the wilderness qualities and cultural resources associated with National Parks' (Swemmer \& Taljaard 2011). In addition, there is a specific tourism objective under the people's objective which aims to develop, manage and enhance a range of sustainable tourism products in synergy with the SANParks conservation ethic.

The purpose of the tourism research framework is to highlight the required research to support the achievement of conservation, tourism and people's objectives and to 
integrate tourism decision-making in the implementation of SAM in SANParks. Research guided by the tourism research framework can play an important role in enhancing the evaluation of the achievement of SANParks' objectives, which is necessary as part of the adaptive planning, implementation and evaluation steps of SAM. Studies that evaluate the importance of iconic mammals, such as lion and elephant, to provide tourists with a high quality, naturebased, value-for-money experience (Di Minin et al. 2013; Lindsey et al. 2007), the socio-economic impact of national parks (Saayman \& Saayman 2010), or the impact of tourism on adjacent communities (Anthony 2007; Strickland-Munro, Allison \& Moore 2010) can provide valuable insights into tourism management when incorporated in the adaptive evaluation process. The intention of the tourism research framework is not only to guide the integration of information for management outcomes but also to be adapted over time as new management needs and objectives emerge.

\section{Development of a tourism research framework}

The development of the tourism research framework followed a number of iterative steps and processes. These included an initial tourism research workshop, the identification of knowledge gaps associated with SANParks' responsible tourism policy, the development of a social-ecological systems understanding of tourism to national parks and conducting an integrated park management planning exercise (Figure 1). In accordance with the principles of SAM, the thinking during the development of the research framework was that it would be evaluated, reviewed and adapted over time.

\section{Initial stakeholder workshop for tourism research}

The development of the tourism research programme was initiated through engaging a variety of stakeholders, including tertiary research institutions, representatives from district municipalities and private companies that were in PPPs with SANParks, in a tourism research workshop held in February 2011.

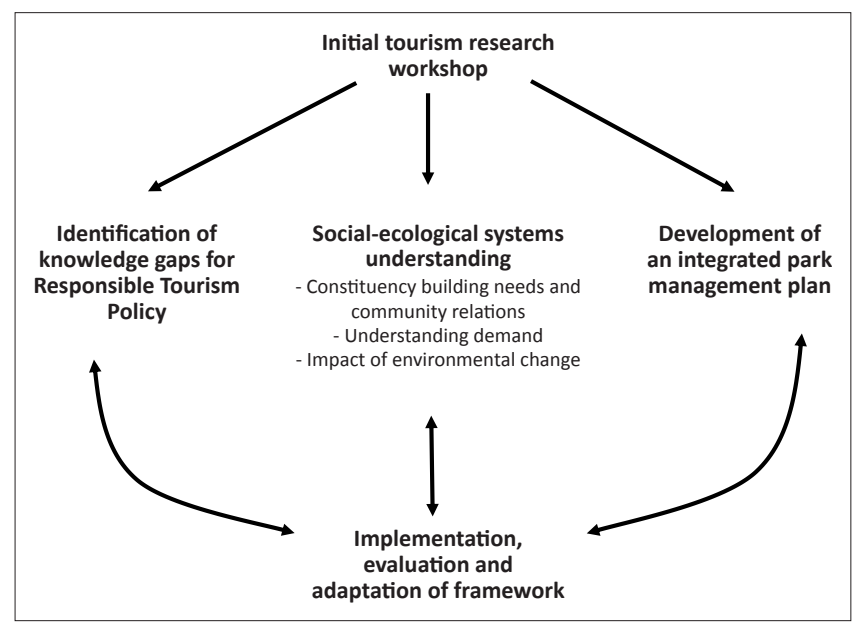

Source: Authors' own creation

FIGURE 1: Process followed for the development of the tourism research framework.
A wide range of SANParks staff also participated. These included members of the Tourism Executive, Policy Development, Corporate Social Investment, Scientific Services, People and Conservation and the Trans-frontier Conservation Areas division. The themes covered in the workshop ranged from managing the trade-offs between biodiversity and economics in tourism, neighbouring community benefits from tourism, cultural tourism, aligning tourism product development with the principles of responsible tourism and meeting tourist demands. The working groups discussed the themes in the context of objectives and prioritised management challenges which were then used to identify information and knowledge gaps. This formed the foundation for the drafting of an expansive set of tourism research needs and a draft tourism research framework was established (Spenceley 2011).

\section{Furthering the research framework}

The further development of the framework took a transdisciplinary approach to research, which recognises that knowledge is co-created between scientists, practitioners and policymakers and that the continual questioning of different disciplinary perspectives is essential (Max-Neef 2005). In addition, such an approach based on complexity thinking integrates biodiversity conservation, ecological, social and economic approaches.

Furthermore, the Tourism Executive expressed the need for tourism decision-making in SANParks to become strategic, structured and evidence-based. From August 2011, extensive discussions took place within Scientific Services, and with the Tourism Executive, to further develop a clear agenda for tourism research by advancing the original framework. With this aim, the following three processes were followed:

- The identification of knowledge gaps and research needs that stem from the SANParks responsible tourism policy adopted by SANParks (Phillips 2012).

- The development of a social-ecological systems diagram of tourism in national parks and the questions that this system's perspective raises.

- Conducting a tourism management planning exercise for a national park, together with the park and regional management and tourism staff.

\section{Identifying knowledge gaps in the implementation of the responsible tourism strategy}

Not only is baseline data required to measure SANPark's progress towards achieving the aims of responsible tourism, but the structures and processes to enable the successful implementation of the policy require understanding (Table 1). The key research areas that were identified during this process were:

- Monitor, evaluate and research the drivers of visitor satisfaction and how it can be improved.

- Assess the levels of, and research the determinants of successful constituency-building for conservation through tourism and how this can be strengthened. 
TABLE 1: Selected principles and associated knowledge gaps and research needs of the South African National Parks responsible tourism strategy.

\begin{tabular}{|c|c|c|}
\hline Principle & Key performance areas & Knowledge gaps and issues \\
\hline $\begin{array}{l}\text { 1. Provide sustainable high quality, } \\
\text { nature-based, value-for-money } \\
\text { tourism experiences whilst } \\
\text { promoting our biodiversity, } \\
\text { cultural and, where applicable, } \\
\text { wilderness qualities to our } \\
\text { strategic advantage. }\end{array}$ & $\begin{array}{l}\text { Good and improving levels of visitor } \\
\text { satisfaction in the following areas: } \\
\text { - natural heritage } \\
\text { - cultural heritage } \\
\text { quality of accommodation, activities and } \\
\text { services, including interpretation. }\end{array}$ & $\begin{array}{l}\text { Develop an understanding of the underlying factors behind visitor satisfaction and changes in } \\
\text { expectations and perceptions. Questions include: } \\
\text { - The current levels of visitor satisfaction? } \\
\text { - In which areas can visitor satisfaction improve? } \\
\text { - What are the primary factors that contribute to visitor satisfaction in national parks? } \\
\text { international visitors)? }\end{array}$ \\
\hline $\begin{array}{l}\text { 2. Contribute to building a broad } \\
\text { constituency for conservation in } \\
\text { a people-centred way. }\end{array}$ & $\begin{array}{l}\text { Good attitudes and positive behaviour } \\
\text { towards national parks by neighbouring } \\
\text { communities, visitors and broader society. }\end{array}$ & $\begin{array}{l}\text { - Current attitude towards national parks and conservation by neighbouring communities, } \\
\text { visitors and broader society. } \\
\text { - Key opportunities and actions to improve these attitudes and strengthen the constituency } \\
\text { for conservation. }\end{array}$ \\
\hline $\begin{array}{l}\text { 3. Using appropriate nature-based } \\
\text { tourism as the best possible } \\
\text { financial opportunity to support } \\
\text { and supplement conservation. } \\
\text { (This financial driver should } \\
\text { never become an end in itself } \\
\text { and should never erode the } \\
\text { core conservation values of the } \\
\text { organisation.) }\end{array}$ & $\begin{array}{l}\text { - Healthy income and profit levels in } \\
\text { SANParks at the scale of individual parks. } \\
\text { - Achievement of desired income and } \\
\text { profit levels but with no or minimal } \\
\text { impact on SANParks conservation, visitor } \\
\text { satisfaction and constituency-building } \\
\text { objectives. } \\
\text { - Ideally, healthy income and profit levels } \\
\text { should be synergic with conservation } \\
\text { and constituency-building objectives. }\end{array}$ & $\begin{array}{l}\text { - Are there activities or services that can be developed that will maximise income relative to } \\
\text { conservation impact? } \\
\text { - The impact of different tourist activities on conservation. } \\
\text { - Are there activities or services that can be developed that can maximise income and } \\
\text { synergise with constituency-building objectives? } \\
\text { - Research the potential for better yield management from tourism income in different } \\
\text { national parks. } \\
\text { - Opportunities to strengthen income through understanding the characteristics and } \\
\text { different segments of SANParks (and individual parks) client base and target marketing } \\
\text { accordingly. }\end{array}$ \\
\hline $\begin{array}{l}\text { 4. Promote mutual benefits with } \\
\text { key stakeholders, as well as } \\
\text { opportunities for growth and } \\
\text { development of neighbouring } \\
\text { communities, bearing in mind } \\
\text { SANParks is not a development } \\
\text { agency. }\end{array}$ & $\begin{array}{l}\text { - Achievement of socio-economic } \\
\text { benefits for neighbouring communities, } \\
\text { stakeholders and broader society. } \\
\text { - Achievement of non-economic } \\
\text { benefits to neighbouring } \\
\text { communities, stakeholders and } \\
\text { broader society (e.g. identity, sense } \\
\text { of community, existence value and } \\
\text { relaxation). }\end{array}$ & $\begin{array}{l}\text { - What are the job creation and economic benefits of national parks and, more broadly, of } \\
\text { SANParks? } \\
\text { - How can the employment and economic contribution of national parks be strengthened? } \\
\text { - How can the non-economic benefits of national parks be strengthened, both to visitors and } \\
\text { neighbouring communities? } \\
\text { - What are the key barriers to enhancing the socio-economic contribution of national parks? } \\
\text { - Which opportunities exist to involve neighbouring communities and other stakeholders to } \\
\text { enhance benefits from tourism to national parks (e.g. the development of cultural tours)? } \\
\text { - How can these funds be distributed to ensure fair access by all? }\end{array}$ \\
\hline
\end{tabular}

Source: Based on Phillips, G., 2012, Responsible tourism in SANParks: 2012-2022 Strategy, SANParks, Pretoria

SANParks, South African National Parks.

- Evaluate and understand the synergies and trade-offs between income from tourism in SANParks and the achievement of conservation and constituency-building objectives and identify opportunities to synergise tourist income with conservation and constituency-building objectives.

In addition, the discussion between Scientific Services and the Tourism Executive generated a range of additional research needs:

- Human capacity and human capital is critical for the functioning of the entire tourism and conservation system and research is needed on how it can be strengthened (Hall 2009).

- The legal and regularity framework governs the way in which tourism products are managed and can be delivered; in other words, management processes, such as procurement procedures and human resource procedures, may affect SANParks' ability to achieve the objectives of the responsible tourism policy. The interaction between these legal and organisation frameworks and the strategic adaptive management of tourism needs to be understood.

- BEE is a key national policy imperative in South Africa and research is needed to understand how the development and management of tourism in SANParks currently contributes to South Africa's imperative for BEE and societal transformation and how this can be improved (SANParks 2012). This research focus transcends the entire organisation, including the structure and management of PPPs. SANParks should enable economic empowerment which empowers marginalised and poor communities (Ashley 2006). Management processes and structures that enable successful transformation but ensure the delivery of top quality tourism services and products need to be researched and developed. An important component of this issue is the research and development of principles and models that can guide partnerships with communities neighbouring parks and other stakeholders so that they can receive more benefits from tourism to national parks. Processes and principles to enable the just, transparent and sustainable distribution of such benefits also require research.

- The role of national parks in forging a common national identity and a sense of national pride (Pretes 2003).

\section{A social-ecological systems perspective}

The role of tourism to PAs in conservation and in generating societal benefits plays out in broader interactive socialecological systems (Ban et al. 2013; Strickland-Munro et al. 2010). An understanding of tourism's relation to national parks needs to therefore account for these broader social-ecological interactions. The development of social-ecological systems diagrams are widely used as a tool to illuminate the dynamics of a system that require understanding for its management (Anderies, Janssen \& Ostrom 2004; Wilkinson 2012). A socialecological systems diagram was developed by Scientific Services and the Tourism Executive to establish whether the process of developing the diagram raised additional considerations and research questions that did not emerge in the stakeholder workshop, or in the analysis of the responsible tourism policy research needs. The social-ecological systems diagram that we developed (Figure 2) provides an outline of the joint understanding of the tourism system in SANParks by Scientific Services and the Tourism Development and Marketing Executive. Below, the key components of the social-ecological systems diagram (Figure 2) and the research needs that stemmed from each are discussed. 


\section{Tourist demand}

Tourist demand and therefore revenue depends on the propensity to travel, which is associated with factors such as, (1) the trendiness of the destination and (2) the value attributed to the travel experience (Biggs 2011; Hjalager 2010). Factors such as concern over carbon emissions from long haul travel may reduce the perceived value of travel to national parks in South Africa and therefore reduce demand (Tol 2007). Affordability is another important factor and depends on issues such as the exchange rate for international visitors and the real cost of visiting national parks (Smeral 2010). Security concerns can also play a powerful role in reducing demand for travel to national parks (Hall, Timothy \& Duval 2004). The tourists' perceptions of the state of the natural or cultural attractions in parks will depend on their expectations, the interpretation and visitor information provided by SANParks and also their knowledge of a system. For example, research on tourists to coral reefs has shown that visitor perception of coral reef condition can be very different from ecological metrics (Andersson 2007; Biggs 2011; Uyarra, Watkinson \& Côté 2009). Different market segments will also differ in their perception - more knowledgeable and experienced tourists are more likely to detect degradation in the environment. The above factors contribute to the expectations of an experience that will result from visiting the destination, which is also an important determinant of tourist demand (Fenton, Young \& Johnson 1998).

The expectations of what an experience may hold depends on a range of factors that, for the purposes of the SANParks tourism research framework, can be summarised into three groups, (1) experiences of past visits, levels of satisfaction (Gnoth 1997), (2) expectations generated by discussions with the social network (Wang, Yu \& Fesenmaier 2002) and (3) exposure and interaction with marketing materials and interaction with travel agents (Middleton et al. 2009).

Levels of visitor satisfaction depend on the interaction between these expectations and the visitor's experience of the PA and its natural and cultural attractions. This experience is mediated by the condition of the tourist infrastructure and facilities and interactions with PA staff.

The development of the social-ecological systems understanding led to the identification of additional research priorities to understand the key risks to continued tourism demand and the tourism revenue stream:

- Perceived security, which partly depends on relationships with neighbouring communities.

- Affordability of SANParks as a destination relative to competitors.

- Expectations of experience and levels of visitor satisfaction.

- Quality of service, infrastructure and facilities.

- Perceived state of natural and cultural attractions.

\section{Relationship with neighbouring communities and broader society}

The relationship between a national park and its neighbouring communities can have an important impact on both the perception of the PA and security concerns (Anthony 2007; Berkes 2007). Engagement by SANParks with neighbouring communities and also broader society will influence the

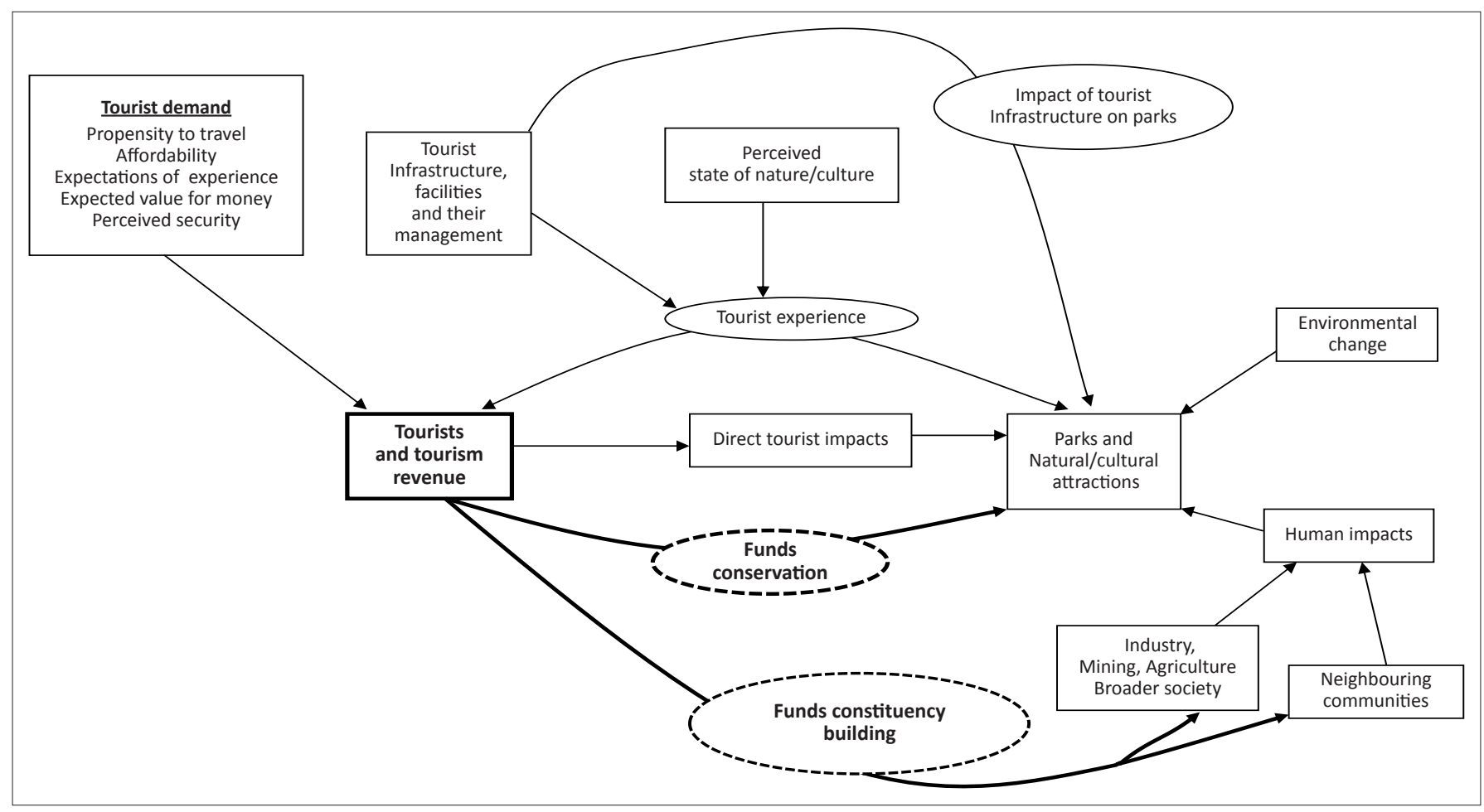

Source: Authors' own creation

Tourist revenue funds both conservation activities, such as purchasing new protected areas and management costs, as well constituency-building with neighbouring communities and broader society, which includes industry and the mining sector and agricultural sectors. These constituency-building efforts can influence human impacts on national parks by, for example, reducing illegal hunting by neighbouring communities or effluent disposal by industry or mining.

FIGURE 2: A social-ecological systems diagram of tourism to national parks. 
perceptions of these stakeholders and potentially affect their actions and therefore the human impacts that they have on parks (Botha et al. 2007). The impacts of neighbouring communities and sectors such as industry and agriculture in broader society include issues such as the illegal harvesting of resources and water extraction from, and pollution of rivers (Figure 2). Importantly, improving the relationship between PAs and neighbouring communities requires the use of a complexity perspective, the ability to deal with multiple objectives through deliberative, participatory processes (Berkes 2007). For SANParks to achieve its constituencybuilding objective, it needs to understand and manage the perception of, and the relationship between, neighbouring communities, broader society and national parks.

Furthermore, building a constituency for conservation requires the strenghtening the relationship between SANParks, neighbouring communities and broader society. This requires the promotion of mutual benefits with key stakeholders, as well as opportunities for growth and development of neighbouring communities, whilst acknowledging that SANParks is not a development agency (Phillips 2012). Key research priorities that can support SANParks in achieving these objectives are:

- What are the job creation and economic benefits of national parks and, more broadly, of SANParks?

- How can the employment and economic contribution of national parks be strengthened?

- How can the non-economic benefits of national parks be strengthened, both to visitors and neighbouring communities?

- What are the key barriers to enhancing the socio-economic contribution of national parks?

- Which opportunities exist to involve neighbouring communities and other stakeholders to enhance benefits from tourism to national parks (e.g. the development of cultural tours)?

- How can the funds and opportunities from SANParks to neighbouring communities and broader stakeholders be distributed to ensure fairer access to all?

\section{Global environmental change}

Global environmental change can influence tourism to PAs in a number of ways (Gossling \& Hall 2006). Climate change receives a lot of attention, but it is the interaction of climate change with pressures, such as invasive species (e.g. see Letnic, Webb \& Shine 2008), bush encroachment (e.g. Blaum et al. 2007; Hudak \& Wessman 1998) and droughts (e.g. Wall \& Badke 1994), that may be of more importance. Since 2000, the Kruger National Park has been affected by a number of substantial floods which have led to a loss of revenue as a result of a lack of access to tourist and accommodation facilities, but which also have had a significant financial burden in the replacement and repair of damaged infrastructure (SANParks 2012). Key research priorities identified with respect to environmental change are:

- What are the key potential risks from environmental change on visitor satisfaction and tourist demand as a result of impacts such as bush encroachment, more frequent and severe flooding and/or droughts?

- What are the repair and maintenance cost and revenue implications of increased frequency and severity of natural disasters such as floods?

- What are the potential risks that environmental change poses to the livelihoods of neighbouring communities (e.g. from more frequent or extreme floods or droughts) and how may these impact on constituency-building efforts and tourism?

\section{Conducting an integrated park management planning exercise}

In addition to the theoretical development and discussions between Scientific Services and the Tourism Executive to strengthen the transdisciplinary nature of the tourism research framework, the revision of an integrated park management plan was part of the process. The management plan for Augrabies Falls National Park (hereafter Augrabies) was due for revision and this was used as an opportunity for a two-day workshop. Representatives of Scientific Services and the Tourism Executive participated in a two-day management planning exercise together with Conservation Management, People and Conservation, and Tourism Management and marketing staff from SANParks based at Augrabies and in the broader region. The objective of the workshop was to integrate tourism planning with the biodiversity conservation plan and the plan for engaging and working with local communities.

The process highlighted the value of a broader SANParks tourism research agenda which can inform (and be informed by) tourism planning at the park level. Every national park will have their own specific research needs and therefore the tourism research framework should be implemented in consideration of the different contexts of each national park. However, a few of the tourism research needs that emerged in Augrabies are likely to be relevant to many national parks. For example, a key issue in Augrabies is the need to understand the market for new products to increase visitor stay and visitor income. In addition, there are numerous local communities in close proximity to Augrabies that can potentially partner with SANParks to deliver cultural tours and products to visitors. This would simultaneously deliver benefits to local communities and increase the diversity of products offered to tourists. The market demand for and the potential partnership models through which such products can be managed needs to be explored. As the tourism management planning process is conducted for other national parks, other park-specific needs may emerge.

\section{Operationalising and funding tourism research \\ Research project facilitation and management}

SANParks has a strong track record over the past decade and a half of coordinating and managing research with scientific partners at universities and research institutions in South Africa and internationally (Du Toit et al. 2003; 
Gaylard \& Ferreira 2011). To date, much of this research has been focused on ecological or biological issues. The aim of the tourism research programme is to foster and conduct high quality research of international standard through partnerships with research institutions to support the SAM of tourism in SANParks.

Tourism research projects will be managed through the same research project management process that is in place for all research projects. Individuals from universities and research agencies that are interested in collaborating with SANParks in conducting tourism research submit a research proposal. The SANParks staff member responsible for coordinating tourism research will work together with the respective individuals to ensure that the research proposal is aligned with SANParks objectives and information needs. Sometimes, commercially oriented research with tight deadlines is required to inform urgent management decisions. Such rapid assessments will follow an alternative faster review system that still aims to ensure the rigour and the value of the research.

\section{Funding options}

Through partnerships with scientific institutions, the cofunding of tourism research is possible. Related funding options include joint applications for industry and research linkage grants (with South African and international institutions) and joint funding of graduate student or research fellowships. Importantly, tourism research expertise and capacity is required within SANParks to coordinate, facilitate and integrate research to ensure that it aligns with SANPark's information needs and can effectively support the practice of SAM within the tourism domain.

\section{Discussion}

\section{Lessons learnt and challenges}

Our article has described one of the first attempts, to our knowledge, of integrating tourism research into the adaptive management policies of a PA agency. The integration of tourism research into the SAM of tourism in SANParks remains a challenge. Despite the development of a tourism research framework jointly between Scientific Services and the Tourism Executive, there is still little integration between tourism management and science and limited progress towards managing tourism within the framework of SAM.

Through the process of developing the tourism research framework and its implementation, we faced a number of challenges and learnt numerous lessons that may be of value to other PA agencies and conservation organisations that attempt to integrate tourism research and decision-making and conservation management in a transdisciplinary fashion. The key issues that we identified are, (1) different objectives and different timeframes for tourism and conservation objectives, (2) auditing and organisational reporting systems that are not congruent with an adaptive approach to management and (3) human and organisational capacity constraints and entrenched ways of thinking about managing tourism. We discuss each of these in turn.

\section{Different cultures of operating, objectives and timeframes}

Tourism managers have to report on short-term financial performance as part of the evaluation of whether annual financial objectives have been met. Their requirements can lead to a very different way of thinking about the type of tourism research that is needed. In essence, there is a tension between a more business-oriented operating culture focused on short-term financial objectives and a conservation management and science culture focused on longer-term, more holistic objectives such as biodiversity conservation and achieving community benefits. These objectives are not necessarily mutually exclusive and they can be aligned (e.g. see Biggs, Ban \& Hall 2012). However, this alignment requires regular interaction between Scientific Services, tourism managers and national park managers. The implementation of the tourism research framework through these regular interactions represents an attempt to implement a novel transdisciplinary, science-based approach to management - a challenging task (Gunderson, Holling \& Light 1995). Closer cooperation between Scientific Services, the Tourism Executive and management both within parks and at national level will be essential to implement SAM and the findings of tourism research effectively and through regular communication and collaboration this cooperation can be achieved.

\section{Legal structures and organisational procedures}

Legal structures and auditing procedures in organisations originate from a perspective of command and control and not one of adapting and learning in a complex, adaptive system (Ebbesson 2010). Although the theory and science of legal practices and auditing is adapting to a more complex world, these changes will take time to filter through to individual PA agencies and conservation organisations. Research and experimentation is required to find ways of managing tourism and conservation more adaptively within existing auditing and legal procedures, as well as to develop new processes that are more adaptive but still satisfy the need for control and regulations of auditors and regulators (Ebbesson 2010).

\section{Entrenched ways of thinking and capacity constraints}

The cognitive frameworks that people use to interpret and the world and make decisions play a critical role in managing the complex interface between tourism and conservation (Biggs, Abel, Knight, Leitch, Langston \& Ban 2011). Entrenched perspectives about what tourists want, how to increase the number of tourists to a PA and how tourism should be managed act as potential constraints to managing the tourism and conservation interface more creatively, with more room for the emergence of synergies between tourism and conservation. However, there are numerous participatory social processes (e.g. Barnaud, Bousquet \& Trebuil 2008; Biggs, Abel, Knight, Leitch, Langston \& Ban 2011; Cundill et al. 2012; Voinov \& Bousquet 2010) which can be used to address this challenge and develop a shared 
vision for action for tourism and conservation based on the co-construction of a shared understanding of a system and the alternative options available.

\section{Research and the strategic adaptive management of tourism}

The aim of the development of the tourism research framework was to strengthen the SAM of tourism in national parks and to integrate research coordinated and guided by Scientific Services into the decisions and policies of the Tourism Executive and individual park managers. The benefits of this integration would be a more holistic consideration of the interactions between biodiversity conservation and tourism in policy and management decisions. However, because of the challenges described above, the collaboration between Scientific Services and the Tourism Executive to achieve this integration has not been sustained. These challenges were not completely unexpected, but perhaps insufficient attention was paid to how these challenges could be managed earlier on in the dialogue between Scientific Services and the Tourism Executive. Implementing a novel transdisciplinary, science-based approach to the adaptive management of tourism through SAM was always going to be challenging (Gunderson et al. 1995). A commitment from both Scientific Services and the Tourism Executive to regular communication, collaboration and the commitment of sufficient resources and human capacity for this collaboration will be necessary. Moreover, both departments need to acknowledge and respect that they operate according to different cultural norms and perspectives with sometimes differing objectives (Biggs, Abel, Knight, Leitch, Langston \& Ban 2011; Cundill et al. 2012). Through such collaborative processes, co-learning between the departments can emerge which together with closer cooperation between Scientific Services and the Tourism Executive and management will be essential to integrate the findings of tourism research effectively within a SAM framework in SANParks.

A further important lesson learnt is that the implementation of tourism research in management decision-making could possibly have been strengthened by collaborating more closely with the managers in individual national parks as well as the Tourism Executive. Many decisions or components are taken at the level of individual national parks and developing the research framework in a more participatory and decentralised way would have enabled the implementation of the research framework to take place at the level of individual national parks as well. The benefits of decentralisation for conservation and natural resource management are widely discussed in the literature (Andersson \& Ostrom 2008; Bohensky 2008).

\section{Conclusion}

In this article, we discussed the development of a transdisciplinary tourism research framework by SANParks. The development of the framework was led by Scientific Services and included extensive interactions with managers at an individual national park, with the Tourism Executive and other stakeholders. The research suggested by this framework is slowly getting underway and SANParks is adapting the framework in accordance with the lessons learnt. We believe that our experiences in integrating tourism research with conservation management can hold valuable lessons for other conservation agencies.

\section{Acknowledgements}

The authors would like to thank the Kruger Park Marathon club for providing financial support to the development of a tourism research framework. In addition, we would like to thank Harry Biggs, Giju Varghese, Marna Herbst and Danie Pienaar who provided their time and insight during the development of the tourism research framework and this article. In addition, we would like to thank two reviewers who provided us with comments to substantially improve this article. Stefan Gelcich at the Pontifica Universidad Catolica de Chile provided office space and resources during the revision stage of this article.

\section{Competing interests}

The authors declare that they have no financial or personal relationships that may have inappropriately influenced them in writing this article.

\section{Authors' contributions}

D.B. (University of Queensland) was the project leader and led the writing of the manuscript. G.P. (SANParks Tourism Managing Executive) and J.S. (SANParks Tourism Managing Executive) participated in workshop discussions and made conceptual contributions. L.S. (SANParks Scientific Services), S.F. (SANParks Scientific Services) and R.G. (SANParks Scientific Services) made conceptual contributions and assisted with writing and editing.

\section{References}

Anderies, J.M., Janssen, M.A. \& Ostrom, E., 2004, 'A framework to analyze the robustness of social-ecological systems from an institutional perspective', Ecology and Society $9,18$.

Andersson, J.E.C., 2007, 'The recreational cost of coral bleaching - A stated and revealed preference study of international tourists', Ecological Economics 62(3-4) 704-715. http://dx.doi.org/10.1016/j.ecolecon.2006.09.001

Andersson, K. \& Ostrom, E., 2008, 'Analyzing decentralized resource regimes from a polycentric perspective', Policy Sciences 41, 71-93. http://dx.doi.org/10.1007/ s11077-007-9055-6

Anthony, B., 2007, 'The dual nature of parks: Attitudes of neighbouring communities towards Kruger National Park, South Africa', Environmental Conservation 34(3), 236-245. http://dx.doi.org/10.1017/S0376892907004018

Ashley, C., 2006, Facilitating pro-poor tourism with the private sector. Lessons learned from pro-poor tourism pilots in southern Africa, Overseas Development Institute, London.

Ban, N.C., Mills, M., Tam, J., Hicks, C.C., Klain, S., Stoeckl, N. et al., 2013, 'A socialecological approach to conservation planning: Embedding social considerations', Frontiers in Ecology and the Environment 11(4), 194-202.

Barnaud, C., Bousquet, F. \& Trebuil, G., 2008, 'Multi-agent simulations to explore rules for rural credit in a highland farming community of northern Thailand', Ecological Economics 66(4), 615-627. http://dx.doi.org/10.1016/j.ecolecon.2007.10.022

Barrett, C.B., Travis, A.J. \& Dasgupta, P., 2011 'On biodiversity conservation and poverty traps', Proceedings of the National Academy of Sciences 108(34), 13907-13912. http://dx.doi.org/10.1073/pnas.1011521108, PMid:21873176, PMCid:PMC3161563

Berkes, F., 2007, 'Community-based conservation in a globalized world', Proceedings of the National Academy of Sciences 104(39), 15188-15193. http://dx.doi.org/ 10.1073/pnas.0702098104, PMid:17881580, PMCid:PMC2000555

Biggs, D., 2011, 'Understanding resilience in a vulnerable industry - The case of reef tourism on Australia's Great Barrier Reef', Ecology \& Society 16(1), 30. 
Biggs, H.C. \& Rogers, K., 2003, 'An adaptive system to link science, monitoring and management in practice', in J.T. du Toit, K.H. Rogers \& H.C. Biggs (eds.), The Kruger management in practice, in J.T. du Toit, K.H. Rogers \& H.C. Biggs (eds.), The Kruger experience: Ecology and
Press, Washington, DC.

Biggs, H., Ferreira, S., Freitag-Ronaldson, S. \& Grant-Biggs, R., 2011, 'Taking stock after a decade: Does the "thresholds of potential concern" concept need a socio-ecological revamp?', Koedoe 53(2), 9 pages. http://dx.doi.org/10.4102/koedoe.v53i2.1002

Biggs, D., Turpie, J., Fabricius, C. \& Spenceley, A., 2011, 'The value of avitourism for community-based conservation - An analysis from South Africa', Conservation and Society 9(1), 80-90. http://dx.doi.org/10.4103/0972-4923.79198

Biggs, D., Abel, N., Knight, A.T., Leitch, A., Langston, A. \& Ban, N.C., 2011, 'The implementation crisis in conservation planning could "mental models" help?', Conservation Letters 4, 169-183. http://dx.doi.org/10.1111/j.1755-263X.2011. 00170.x

Biggs, D., Ban, N.C. \& Hall, C.M., 2012, 'Lifestyle values, resilience, and nature-based tourism's contribution to conservation on Australia's Great Barrier Reef', Environmenta Conservation 39(4), 370-379. http://dx.doi.org/10.1017/S0376892912000239

Blaum, N., Rossmanith, E., Popp, A. \& Jeltsch, F., 2007, 'Shrub encroachment affects mammalian carnivore abundance and species richness in semiarid rangelands', Acta Oecologica 31(1), 86-92. http://dx.doi.org/10.1016/j.actao.2006.10.004

Bohensky, E.L., 2008, 'Discovering resilient pathways for South African water management: Two frameworks for a vision', Ecology and Society 13, Artcile 19.

Botha, J., Witkofski, E.T.F. \& Cock, J., 2007, 'Is "something better than nothing"? The impacts of ten outreach nurseries on South African community stakeholders', Forests, Trees and Livelihoods 17, 199-221. http://dx.doi.org/10.1080/1472802 Forests, Trees and
8.2007 .9752597

Cundill, G., Cumming, G.S., Biggs, D. \& Fabricius, C., 2012, 'Soft systems thinking and social learning for adaptive management', Conservation Biology 26(1), 13-20. http:// dx.doi.org/10.1111/j.1523-1739.2011.01755.x, PMid:22010884

Dharmaratne, G.S., Yee Sang, F. \& Walling, L.J., 2000, 'Tourism potentials for financing protected areas', Annals of Tourism Research 27(3), 590-610. http://dx.doi.org/ 10.1016/S0160-7383(99)00109-7

Di Minin, E., Fraser, I., Slotow, R. \& Macmillan, D.C., 2013, ‘Understanding heterogeneous preference of tourists for big game species: Implications for conservation and management', Animal Conservation 16, 249-258. http://dx.doi.org/10.1111/ j.1469-1795.2012.00595.x

Du Toit, J.T., Rogers, K.H. \& Biggs, H.C., 2003, The Kruger experience: Ecology and management of savanna heterogeneity, Island Press, Washington, DC.

Ebbesson, J., 2010, 'The rule of law in governance of complex socio-ecological changes', Global Environmental Change 20, 414-422. http://dx.doi.org/10.1016/j. gloenvcha.2009.10.009

Fenton, D.M., Young, M. \& Johnson, V.Y., 1998, 'Re-presenting the great barrier reef to tourists: Implications for tourist experience and evaluation of coral reef reef to tourists: Implications for tourist experience and evaluation of coral
environments', Leisure Sciences: An Interdisciplinary Journal 20(3), 177-192.

Gaylard, A. \& Ferreira, S., 2011, 'Advances and challenges in the implementation of strategic adaptive management beyond the Kruger National Park - Making linkages between science and biodiversity management', Koedoe 53(2), 8 pages. http:// dx.doi.org/10.4102/koedoe.v53i2.1005

Gnoth, J., 1997, 'Tourism motivation and expectation formation', Annals of Tourism Research 24(2), 283-304. http://dx.doi.org/10.1016/S0160-7383(97)80002-3

Gossling, S. \& Hall, C.M., 2006, Tourism and global environmental change, Routledge, Abingdon.

Grant, R.C.C., Peel, M.J.S. \& Bezuidenhout, H., 2011, 'Evaluating herbivore management outcomes and associated vegetation impacts', Koedoe 53(2), 15 pages.

Gunderson, L.H., Holling, C. \& Light, S.S., 1995, Barriers and bridges to the renewal of ecosystems and institutions, Columbia University Press, New York.

Hall, C.M., 2009, 'Tourism firm innovation and sustainability', in S. Gössling, C.M. Hall \& D. Weaver (eds.), Sustainable tourism futures: Perspectives on systems, restructuring and innovations, pp. 282-298, Routledge, New York. PMCid:PMC2677279

Hall, C.M., Timothy, D. \& Duval, D., 2004, Safety and security in tourism: Relationships, management and marketing, Haworth Press, New York.

Hjalager, A.-M., 2010, 'A review of innovation research in tourism', Tourism Management 31(1), 1-12. http://dx.doi.org/10.1016/j.tourman.2009.08.012

Hudak, A.T. \& Wessman, C.A., 1998, 'Textural analysis of historical aerial photography to characterize woody plant encroachment in South African savanna', Remote Sensing of Environment 66(3), 317-330. http://dx.doi.org/10.1016/S0034-4257 (98)00078-9

Letnic, M., Webb, J.K. \& Shine, R., 2008, 'Invasive cane toads (Bufo marinus) cause mass mortality of freshwater crocodiles (Crocodylus johnstoni) in tropical Australia', Biological Conservation 141(7), 1773-1782. http://dx.doi.org/10.1016/j. biocon.2008.04.031

Licht, D.S., Slotow, R. \& Millspaugh, J., 2008, 'Out of Africa: Lessons from park management in South Africa', The George Wright Forum 25, 20-29.

Lindsey, P.A., Alexander, R., Mills, M.G.L., Romanach, S. \& Woodroffe, R., 2007, 'Wildlife viewing preferences of visitors to protected areas in South Africa: Implications for the role of ecotourism in conservation', Journal of Ecotourism 6, 19-33. http:// dx.doi.org/10.2167/joe133.0
Max-Neef, M.A., 2005, 'Foundations of transdisciplinarity', Ecological Economics 53(1), 5-16. http://dx.doi.org/10.1016/j.ecolecon.2005.01.014

Middleton, V.T.C., Fyall, A., Morgan, M. \& Ranchod, A., 2009, Marketing in travel and tourism, Eslevier, Oxford.

Myers, N., Mittermeier, R.A., Mittermeier, C.G., Da Fonseca, G.A.B. \& Kent, J., 2000 'Biodiversity hotspots for conservation priorities', Nature 403, 853-858. http:// dx.doi.org/10.1038/35002501, PMid:10706275

Naidoo, R. \& Adamowicz, W.L., 2005, 'Biodiversity and nature-based tourism at forest reserves in Uganda', Environment and Development Economics 10, 159-178. http://dx.doi.org/10.1017/S1355770X0400186X

Naughton-Treves, L., Buck Holland, M. \& Brandon, K., 2005, 'The role of protected areas in conserving biodiversity and sustaining local livelihoods', Annual Review of Environmental Resources 30, 219-252. http://dx.doi.org/10.1146/annurev. energy.30.050504.164507

Phillips, G., 2012, Responsible tourism in SANParks: 2012-2022 Strategy, SANParks, Pretoria.

Pretes, M., 2003, 'Tourism and nationalism', Annals of Tourism Research 30(1), 125-142. http://dx.doi.org/10.1016/S0160-7383(02)00035-X

South African National Parks, 2012, South African National Parks annual report 20102011, SANParks, Pretoria.

Saayman, M. \& Saayman, A., 2010, 'Regional development and national parks in South Africa: Lessons learned', Tourism Economics 16, 1037-1064. http://dx.doi.org/ 10.5367/te.2010.0007

Roux, D.J. \& Foxcroft, L.C., 2011, 'The development and application of adaptive management in South African National Parks', Koedoe 53(2), 5 pages. http://dx.doi. org/10.4102/koedoe.v53i2.1049

Roux, D.J., Rogers, K.H., Biggs, H.C., Ashton, P.J. \& Sergeant, A., 2006, 'Bridging the science-management divide: Moving from unidirectional knowledge transfer to knowledge interfacing and sharing', Ecology and Society 11(1), Article 4.

Smeral, E., 2010, 'Impacts of the world recession and economic crisis on tourism: Forecasts and potential risks', Journal of Travel Research 49(1), 31-38. http://dx.doi. Forecasts and potential risks', Journ
org/10.1177/0047287509353192

Spenceley, A., 2008, Responsible tourism: Critical issues for conservation and development, Earthscan, London.

Spenceley, A., 2011, 'A tourism research workshop for South African National Parks, 01-02 February 2011', South African National Parks, Pretoria.

Stevenson-Hamilton, J., 1937, South African Eden, Penguin, Johannesburg.

Stirzaker, R.J., Roux, D. \& Biggs, H.C., 2011, 'Learning to bridge the gap between adaptive management and organisational culture', Koedoe 53(2), 6 pages. http:// dx.doi.org/10.4102/koedoe.v53i2.1007

Swemmer, L.K. \& Taljaard, S., 2011, 'SANParks, people and adaptive management: Understanding a diverse field of practice during changing times', Koedoe 53(2), 7 pages. http://dx.doi.org/10.4102/koedoe.v53i2.1017

Strickland-Munro, J.K., Allison, H.E. \& Moore, S.A., 2010, 'Using resilience concepts to investigate the impacts of protected area tourism on communities', Annals of Tourism Research 37, 499-519. http://dx.doi.org/10.1016/j.annals.2009.11.001

Thur, S.M., 2010, 'User fees as sustainable financing mechanisms for marine protected areas: An application to the Bonaire National Marine Park', Marine Policy 34(1) 63-69. http://dx.doi.org/10.1016/j.marpol.2009.04.008

Tol, R.S.J., 2007, 'The impact of a carbon tax on international tourism', Transportation Research Part D: Transport and Environment 12(2), 129-142. http://dx.doi.org/ 10.1016/j.trd.2007.01.004

Uyarra, M., Watkinson, A. \& Côté, I., 2009, 'Managing dive tourism for the sustainable use of coral reefs: Validating diver perceptions of attractive site features', Environmental Management 43(1), 1-16. http://dx.doi.org/10.1007/s00267-0089198-z, PMid:18810525

Van Wilgen, B.W. \& Biggs, H.C., 2011, 'A critical assessment of adaptive ecosystem management in a large savanna protected area in South Africa', Biological Conservation 144, 1179-1187. http://dx.doi.org/10.1016/j.biocon.2010.05.006

Varghese, G., 2008, 'Public-private partnerships in South African National Parks: The rationale, benefits, and lessons learnt', in A. Spenceley (ed.), Responsible tourism: Critical issues for conservation and development, pp. 69-84, Earthscan, London.

Venter, F.J., Naiman, R.J., Biggs, H.C. \& Pienaar, D.J., 2008, 'The evolution of conservation management philosophy: Science, environmental change and social adjustments in Kruger National Park', Ecosystems 11(2), 173-192. http://dx.doi.org/10.1007/ s10021-007-9116-x

Voinov, A. \& Bousquet, F., 2010, 'Modelling with stakeholders', Environmental Modelling and Software 25(11), 1268-1281. http://dx.doi.org/10.1016/j.envsoft.2010.03.007

Wall, G. \& Badke, C., 1994, 'Tourism and climate change: An international perspective', Journal of Sustainable Tourism 2(4), 193-203. http://dx.doi.org/10.1080/0966958 9409510696

Wang, Y., Yu, Q. \& Fesenmaier, D.R., 2002, 'Defining the virtual tourist community: Implications for tourism marketing', Tourism Management 23(4), 407-417. http:// dx.doi.org/10.1016/S0261-5177(01)00093-0

Wilkinson, C., 2012, 'Social-ecological resilience: Insights and issues for planning theory', Planning Theory 11(2), 148-169. http://dx.doi.org/10.1177/1473095211426274 